\title{
Tides in the Mandovi and Zuari estuaries, Goa, west coast of India
}

\author{
D SUNDAR and S R SHETYE
}

Physical Oceanography Division, National Institute of Oceanography, Dona Paula, Goa 403 004, India.

\begin{abstract}
Mandovi and Zuari are two estuaries located in Goa, west coast of India. Variation of water level in the estuaries was monitored for a month at 13 locations using tide-poles during March-April 2003. Analysis of this data has provided for the first time, characteristics of how tidal constituents vary in the narrow and shallow estuaries, typical of those found along the west coast of India. At a distance of $45 \mathrm{~km}$ from the mouth the tidal range increased in both estuaries by approximately $20 \%$. The tidal range at the upstream end of the two channels at the stations dropped sharply because of the increase in elevation of the channels.
\end{abstract}

\section{Introduction}

Located along the west coast of India are a number of estuarine channels that connect the Arabian Sea to the rivers that originate in the Western Ghats mountain range. The Western Ghats rise sharply from the coastline to an average height of about $1000 \mathrm{~m}$. The runoff in the rivers is high during June-September when the Indian summer monsoon is active. At this time winds along the coast are approximately westerly and carry moisture picked up during their passage over the north Indian Ocean, including the Arabian Sea. As a result, the windward side of the Ghats receives high precipitation due to the topographic effect. The rainfall along the central west coast of India is about $250 \mathrm{~cm}$ during June-September.

The Mandovi and the Zuari are two estuaries that are located along the west coast, in Goa (figure 1). Each of these two estuaries is about $5 \mathrm{~m}$ deep. Their cross-sectional area decreases from mouth to head, and tides occur in the two estuaries up to a distance of about $50 \mathrm{~km}$ (Shetye et al 1995). The increase in elevation of the estuarine channels prevents tides from propagating beyond this distance. The runoff in the two estuaries is highly seasonal, just as is the precipitation. This can be seen from figure 2 that gives runoff measured by a gauge located at Ganjem on the Mandovi river (figure 1). The gauge is located just beyond the distance up to which variation in water level due to tides is observed in the channel. The runoff recorded by the gauge is typical of the runoff observed in the rivers located along the west coast. The runoff peaks during the most active phase of the Indian summer monsoon, decreases rapidly after withdrawal of the monsoon and remains negligible from about January till the onset of the next monsoon which generally occurs during late May or early June.

The flow in the estuarine channels is primarily tidal after withdrawal of the monsoon, and continues to be so until onset of the next monsoon. In 1993, tide pole measurements were carried out at 15 locations in the two estuaries for three days. The inferences derived from analysis of these data were that the amplitude of the tide remains virtually unchanged in the channels, and that phase propagates from mouth to head with an average speed of about $6 \mathrm{~m} / \mathrm{s}$ (Shetye et al 1995). However, the time-series of the data collected then, being only 3 days long, did not permit determination of characteristics of tidal constituents.

During March-April 2003, tide pole measurements similar to those during 1993 were carried out at 13 locations by recording the water level

Keywords. Harmonic analysis; tidal constituents; tide-pole; amplification; channel geometry. 


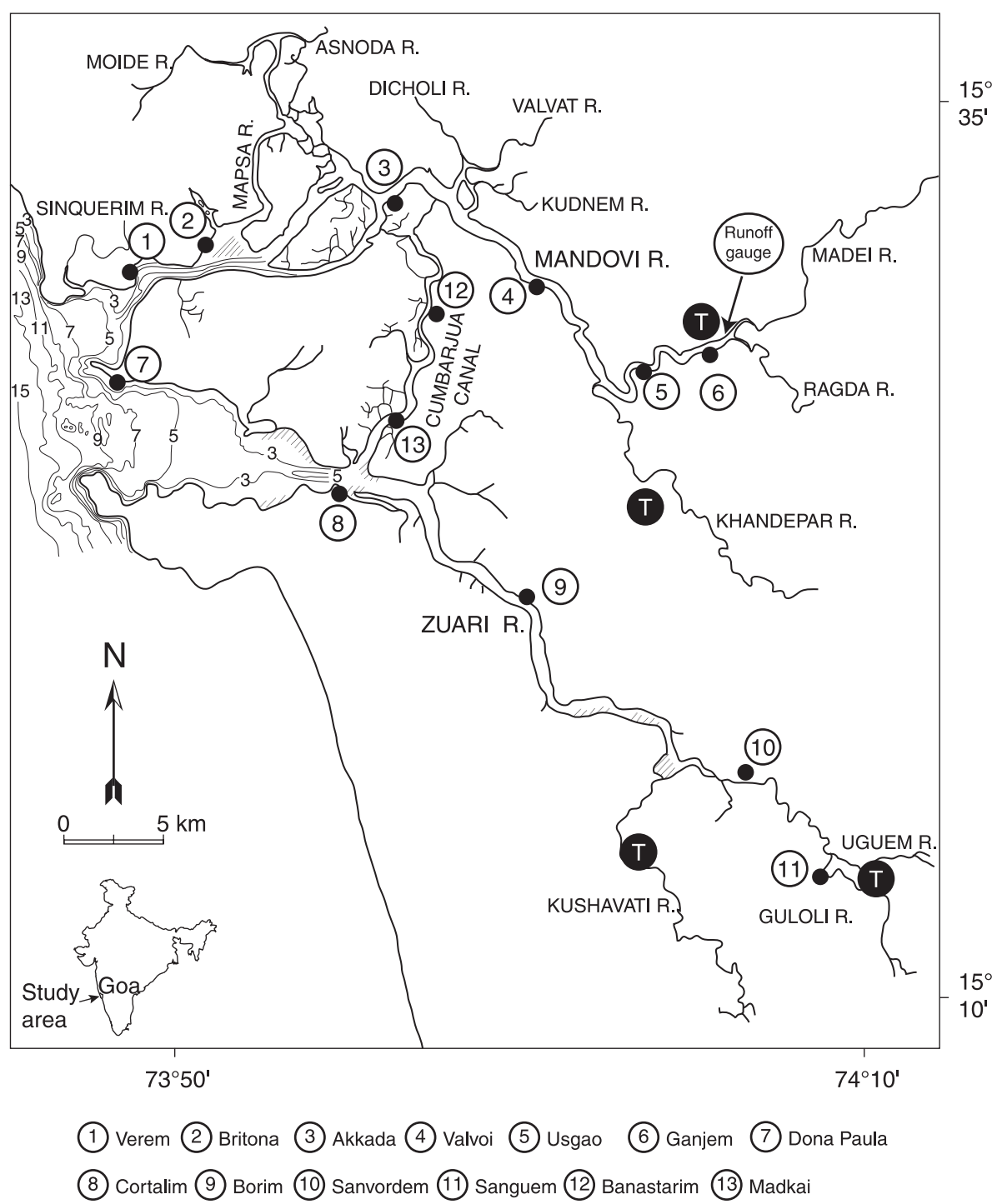

Figure 1. A map of the Mandovi and Zuari estuaries. The locations where water level observations were carried out are marked with a number in a circle. The name of the location is given at the bottom of the map. (T indicates the location up to which variation in water level has been reported to occur. The depth contours are in $\mathrm{m}$.

once every fifteen minutes. In the present paper we report analysis of these data. The new timeseries, being at least 30 days long, allows us to carry out tidal analysis of 34 constituents. The next section describes the data collected and the method of analysis. The results are presented in section 3 . Section 4 provides a brief summary of the study.

\section{Data collection and analysis}

The 13 locations where tide pole measurements were carried out during March-April 2003 are shown in figure 1 . The zero of each tide-pole used in the observations was referenced to a 'local chartdatum' for future reference. The tide pole readers worked in three shifts during a day. Each reader was requested to visually average the water level for about a minute and then record the average water level. It is, however, not clear what the error associated with such a measurement is. Below we make an estimate of the error involved in the estimation of amplitude and phase lag of each constituent.

The distance of each of the 13 stations from the mouth, and start-and-end time of observation are given in table 1 . The 15-minute data were analyzed using TASK-2000 (Tidal Analysis Software Kit 2000) of the Permanent Service for Mean Sea Level, Proudman Oceanography Laboratory, UK (Bell et al 1998) to determine tidal amplitude and phase lag of 26 major constituents and 8 related constituents. The analysis served as a tool for quality control too. Data points with large residuals were examined to determine if the residuals 


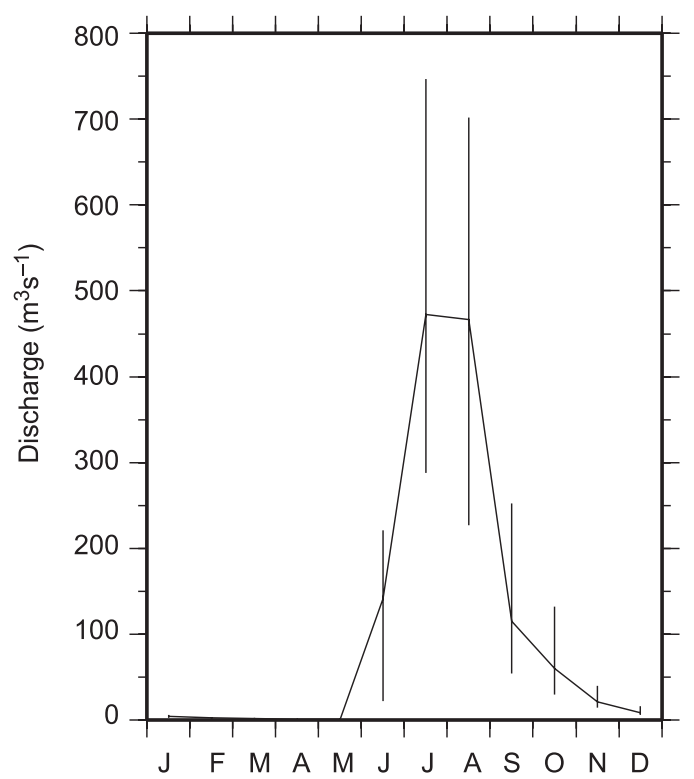

Figure 2. Monthly-mean runoff $\left(\mathrm{m}^{3} / \mathrm{s}\right)$ at Ganjem in the Mandovi river (for location see figure 1). The top (bottom) of an error bar represents the maximum (minimum) discharge during a month. Climatological data (1980-97). Courtesy: Central Water Commission, New Delhi.

were due to errors in recording. If inferred to be so, the suspect data were removed. All computations are referenced to the Indian Standard Time which leads the Greenwich Mean Time by 330 minutes.

The main channels of the Mandovi and the Zuari are connected by the Cumbarjua Canal. Its cross-sectional area is, however, much too small to have a major impact on the characteristics of tidal propagation in the two main channels. Of the 13 stations where the observations were carried out, 6 were located in the Mandovi main channel, 5 in the Zuari main channel, and 2 in the Cumbarjua Canal (figure 1). The quality controlled data at these 13 locations are shown in figure 3. Tidal analysis was carried out at only 11 stations. The water level variation at Ganjem and Sanguem was found to exhibit tidal effect only a part of the time. This is so because of the higher topographic elevation of these stations. We have discussed this point in section 3.2. The data from these stations were not subjected to tidal analysis.

Noting that the Mandovi-Zuari is the only estuarine system along the west coast of India where variation of amplitude and phase lag along the length of the estuarine channel is now known, we provide in tables 2 and 3 all the inferred tidal characteristics at the 11 locations. Of the 34 constituents whose amplitudes and phases were determined, 5 constituents $-\mathrm{M}_{2}, \mathrm{~S}_{2}, \mathrm{~N}_{2}, \mathrm{~K}_{1}$, and $\mathrm{O}_{1}$ - had amplitudes larger than $10 \mathrm{~cm}$ at the mouth of the two estuaries. In the next section we discuss the behaviour of these constituents.

In the rest of this section we make an estimate of the error associated with our determination of amplitude and phase lag of the 34 constituents listed in tables 2 and 3 . The procedure followed for this purpose is as follows: The amplitudes and phase lags given in tables 2 and 3 were computed from time-series with 15 minute separation between consecutive values. The amplitudes and phase lags were recomputed using a time series in which the time interval between two consecutive values was two hours. As the original data are

Table 1. Distance of each of the 13 stations where the observations were carried out and the start-and-end time of the observations.

\begin{tabular}{|c|c|c|c|}
\hline Station & $\begin{array}{l}\text { Distance from } \\
\text { mouth }(\mathrm{km})\end{array}$ & Start time & End time \\
\hline \multicolumn{4}{|l|}{ Mandovi } \\
\hline Verem & 4.81 & 0000 hrs/10th March & 2345 hrs/13th April \\
\hline Britona & 8.86 & 0000 hrs/10th March & $2345 \mathrm{hrs} / 13 \mathrm{th}$ April \\
\hline Akkada & 20.31 & 0000 hrs/10th March & 2345 hrs/13th April \\
\hline Volvoi & 32.91 & 0000 hrs/10th March & 2345 hrs/13th April \\
\hline Usgao & 41.07 & 0000 hrs/10th March & 2345 hrs/13th April \\
\hline Ganjem & 49.83 & 0000 hrs/10th March & 2345 hrs/13th April \\
\hline \multicolumn{4}{|l|}{ Zuari } \\
\hline Dona Paula & 0.00 & 0000 hrs/11th March & 2345 hrs/13th April \\
\hline Cortalim & 11.70 & 0000 hrs/10th March & 2345 hrs/13th April \\
\hline Borim & 21.02 & 0000 hrs/10th March & 2345 hrs/13th April \\
\hline Sanvordem & 45.22 & 0000 hrs/10th March & 2345 hrs/13th April \\
\hline Sanguem & 54.94 & 0000 hrs/11th March & 2345 hrs/13th April \\
\hline \multicolumn{4}{|c|}{ Cumbarjua canal from Dona Paula through Zuari } \\
\hline Madkai & 14.74 & 0000 hrs/10th March & 2345 hrs/13th April \\
\hline Banastarim & 24.61 & 0000 hrs $/ 10$ th March & $2345 \mathrm{hrs} / 13 \mathrm{th}$ April \\
\hline
\end{tabular}




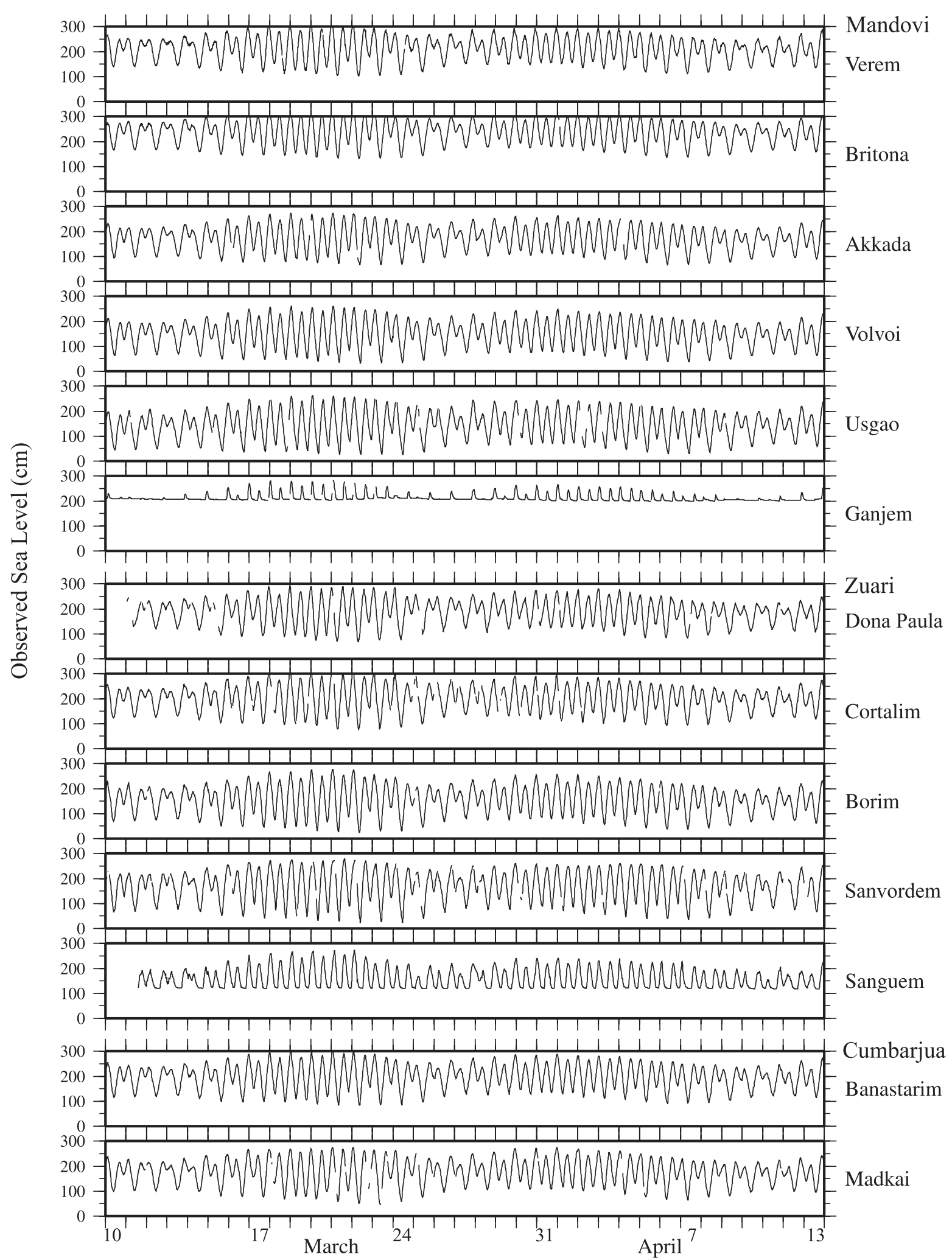

Figure 3. Observed sea level $(\mathrm{cm})$ during the period of observation. The horizontal axis gives date and month.

separated by 15 minutes, we get 8 independent 2 -hour time series. From these we get 8 values for amplitude and phase lag of each constituent at a station. We then computed standard deviation of both amplitude and phase lag. We take the standard deviation to be indicative of the error associated with our determination of amplitudes and phase lag. Tables 4 and 5 give the values obtained through this exercise at one station, Akkada in the Mandovi (location 3 in figure 1). 


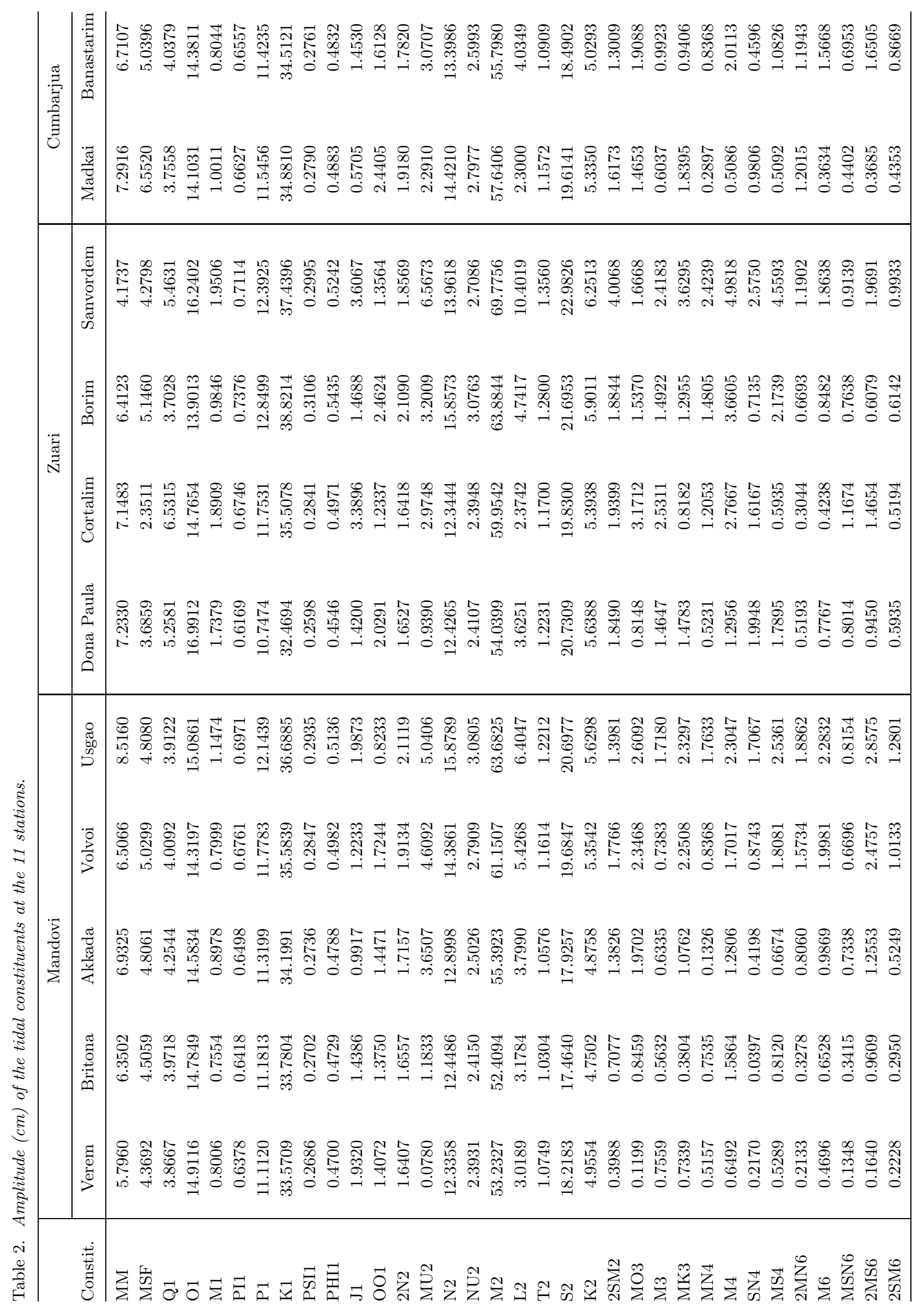




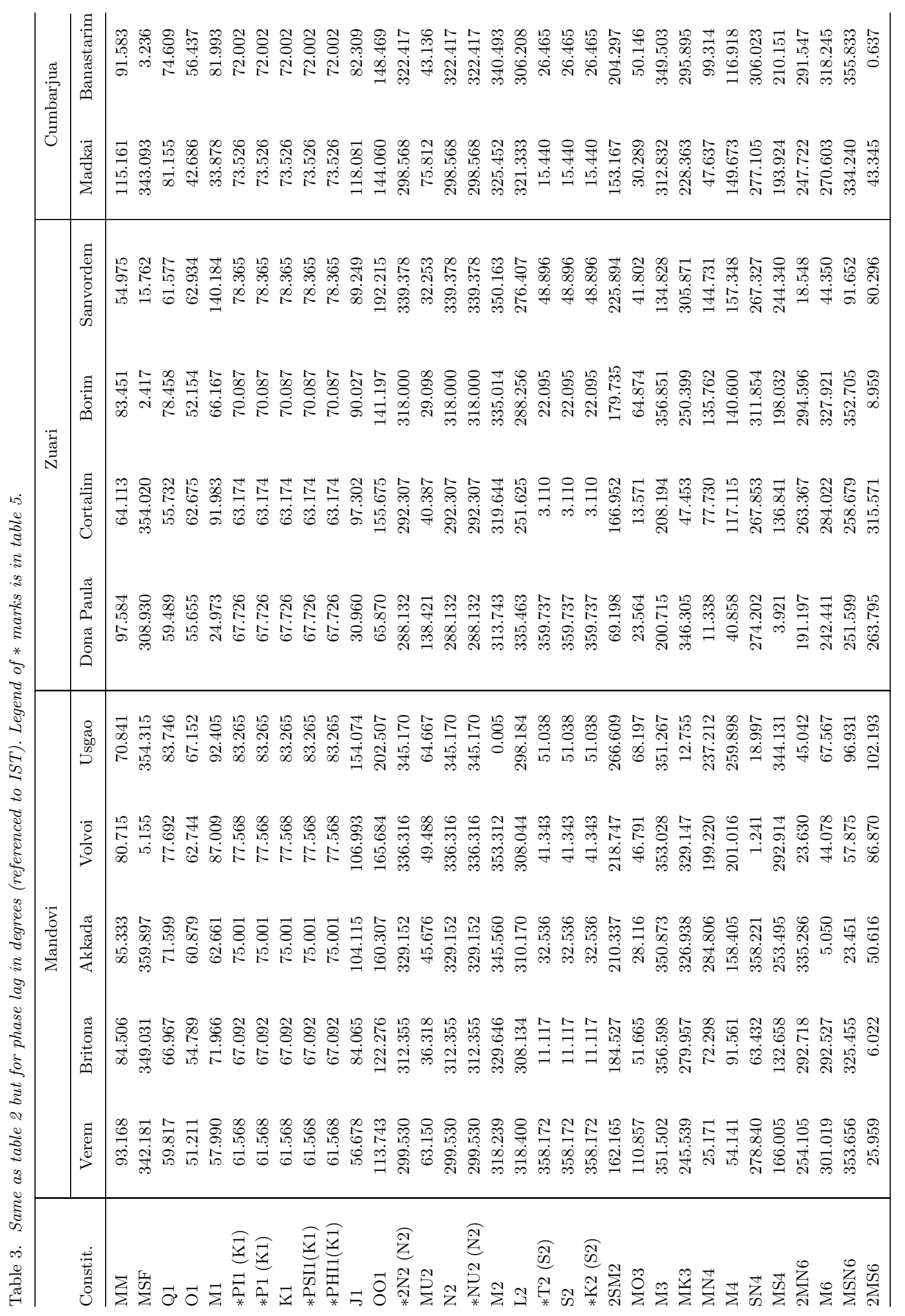


Table 4. Estimation of error (cm) associated with the determination of amplitude (cm) at Akkada. From the original data at 15 min intervals, 8 data sets were derived by sub-sampling at 2-hour intervals. The column x000 contains the data from values at $0000 \mathrm{hr}, 0200 \mathrm{hr}, 0400 \mathrm{hr}$ and so on. The column x015 contains the data from values at $0015 \mathrm{hr}, 0215,0415$ and so on. Similar is the case for $x 030, x 045, x 100, x 115, x 130$ and $x 145$. The mean and standard deviation were calculated using these eight columns. The values in the column $x$ are from ALL the original values from data at 15 min intervals.

\begin{tabular}{|c|c|c|c|c|c|c|c|c|c|c|c|}
\hline Constit. & x000 & x015 & x030 & x045 & x100 & x115 & x130 & x145 & Mean & $\begin{array}{l}\text { Std. } \\
\text { dev. }\end{array}$ & $\mathrm{x}$ \\
\hline MM & 6.88 & 7.03 & 6.99 & 6.89 & 6.89 & 6.94 & 6.90 & 6.94 & 6.93 & 0.052 & 6.93 \\
\hline MSF & 4.79 & 4.94 & 4.82 & 4.75 & 4.83 & 4.85 & 4.75 & 4.73 & 4.81 & 0.065 & 4.81 \\
\hline Q1 & 4.20 & 4.21 & 4.29 & 4.35 & 4.33 & 4.18 & 4.24 & 4.25 & 4.26 & 0.058 & 4.25 \\
\hline O1 & 14.59 & 14.63 & 14.57 & 14.61 & 14.47 & 14.47 & 14.60 & 14.72 & 14.58 & 0.080 & 14.58 \\
\hline M1 & 0.87 & 0.91 & 0.89 & 0.84 & 0.93 & 0.93 & 0.91 & 0.91 & 0.90 & 0.028 & 0.90 \\
\hline PI1 & 0.65 & 0.65 & 0.65 & 0.65 & 0.65 & 0.65 & 0.65 & 0.65 & 0.65 & 0.001 & 0.65 \\
\hline $\mathrm{P} 1$ & 11.34 & 11.34 & 11.31 & 11.29 & 11.36 & 11.33 & 11.29 & 11.30 & 11.32 & 0.023 & 11.32 \\
\hline K1 & 34.25 & 34.26 & 34.16 & 34.12 & 34.31 & 34.24 & 34.12 & 34.12 & 34.20 & 0.070 & 34.20 \\
\hline PSI1 & 0.27 & 0.27 & 0.27 & 0.27 & 0.27 & 0.27 & 0.27 & 0.27 & 0.27 & 0.001 & 0.27 \\
\hline PHI1 & 0.48 & 0.48 & 0.48 & 0.48 & 0.48 & 0.48 & 0.48 & 0.48 & 0.48 & 0.001 & 0.48 \\
\hline $\mathrm{J} 1$ & 0.94 & 0.93 & 0.85 & 0.91 & 1.09 & 1.11 & 1.07 & 1.06 & 1.00 & 0.092 & 0.99 \\
\hline OO1 & 1.31 & 1.37 & 1.37 & 1.53 & 1.68 & 1.54 & 1.42 & 1.34 & 1.45 & 0.119 & 1.45 \\
\hline $2 \mathrm{~N} 2$ & 1.73 & 1.71 & 1.70 & 1.71 & 1.70 & 1.72 & 1.73 & 1.73 & 1.72 & 0.011 & 1.72 \\
\hline MU2 & 3.74 & 3.74 & 3.71 & 3.75 & 3.65 & 3.46 & 3.57 & 3.59 & 3.65 & 0.097 & 3.65 \\
\hline N2 & 12.98 & 12.83 & 12.79 & 12.86 & 12.81 & 12.91 & 13.03 & 12.99 & 12.90 & 0.086 & 12.90 \\
\hline NU2 & 2.52 & 2.49 & 2.48 & 2.49 & 2.48 & 2.50 & 2.53 & 2.52 & 2.50 & 0.017 & 2.50 \\
\hline M2 & 55.43 & 55.32 & 55.25 & 55.25 & 55.26 & 55.41 & 55.68 & 55.53 & 55.39 & 0.144 & 55.39 \\
\hline L2 & 3.73 & 3.87 & 3.96 & 3.79 & 3.89 & 3.78 & 3.72 & 3.67 & 3.80 & 0.090 & 3.80 \\
\hline $\mathrm{T} 2$ & 1.05 & 1.06 & 1.06 & 1.07 & 1.06 & 1.05 & 1.05 & 1.05 & 1.06 & 0.005 & 1.06 \\
\hline $\mathrm{S} 2$ & 17.86 & 17.96 & 17.96 & 18.10 & 17.98 & 17.85 & 17.86 & 17.84 & 17.93 & 0.084 & 17.93 \\
\hline $\mathrm{K} 2$ & 4.86 & 4.89 & 4.89 & 4.92 & 4.89 & 4.85 & 4.86 & 4.85 & 4.88 & 0.023 & 4.88 \\
\hline 2SM2 & 1.55 & 1.52 & 1.31 & 0.99 & 1.26 & 1.49 & 1.55 & 1.50 & 1.39 & 0.183 & 1.38 \\
\hline MO3 & 1.81 & 2.04 & 2.04 & 2.00 & 2.02 & 2.02 & 1.96 & 1.87 & 1.97 & 0.079 & 1.97 \\
\hline M3 & 0.74 & 0.62 & 0.59 & 0.67 & 0.64 & 0.51 & 0.64 & 0.73 & 0.64 & 0.069 & 0.63 \\
\hline MK3 & 1.08 & 1.07 & 1.13 & 0.95 & 1.09 & 1.22 & 1.17 & 0.96 & 1.08 & 0.088 & 1.08 \\
\hline MN4 & 0.31 & 0.26 & 0.29 & 0.38 & 0.31 & 0.30 & 0.36 & 0.14 & 0.30 & 0.067 & 0.13 \\
\hline M4 & 1.37 & 1.29 & 1.26 & 1.19 & 1.17 & 1.26 & 1.30 & 1.42 & 1.28 & 0.079 & 1.28 \\
\hline SN4 & 0.25 & 0.27 & 0.39 & 0.56 & 0.63 & 0.64 & 0.41 & 0.29 & 0.43 & 0.151 & 0.42 \\
\hline MS4 & 0.86 & 0.62 & 0.69 & 0.56 & 0.53 & 0.58 & 0.74 & 0.80 & 0.67 & 0.111 & 0.67 \\
\hline 2MN6 & 0.82 & 0.91 & 0.87 & 0.78 & 0.73 & 0.68 & 0.77 & 0.91 & 0.81 & 0.078 & 0.81 \\
\hline M6 & 1.10 & 1.01 & 1.00 & 0.89 & 0.90 & 0.94 & 1.07 & 1.08 & 1.00 & 0.075 & 0.99 \\
\hline MSN6 & 0.71 & 0.48 & 0.59 & 0.76 & 0.79 & 0.93 & 0.94 & 0.84 & 0.76 & 0.151 & 0.73 \\
\hline 2MS6 & 1.45 & 1.41 & 1.40 & 1.21 & 1.11 & 1.13 & 1.21 & 1.14 & 1.26 & 0.130 & 1.26 \\
\hline 2SM6 & 0.58 & 0.46 & 0.33 & 0.37 & 0.56 & 0.65 & 0.76 & 0.62 & 0.54 & 0.137 & 0.52 \\
\hline
\end{tabular}

After examining the corresponding tables at all the stations, we concluded that for all constituents whose amplitude is greater than $3 \mathrm{~cm}$, the upper limit of the error bar of the values listed in tables 4 and 5 is $\pm 0.5 \mathrm{~cm}$ for amplitude and $\pm 5^{\circ}$ for phase lag.

\section{Results}

\subsection{Distribution of amplitude and phase lag}

Variation of amplitude and phase lag with distance from mouth to head in an estuary with a converging, narrow and shallow channel can be looked at as resulting from two waves: an incident shallow-water wave triggered by the tide at the mouth and a reflected shallow-water wave that gets generated as the incident wave propagates through the channel. In some channels the contribution of the reflected wave can be neglected (Friedrichs and Aubrey 1994). In general, however, both the waves need to be taken into account. When they are, the variation of amplitude and phase difference along the channel is a function of friction, geometry of the channel (rate of convergence of the channel from mouth 
Table 5. Same as table 4 but for the phase lag in degrees (referenced to IST) at Akkada. The 'star' marked entries are related constituents which have not been computed independently, but computed in relation to the independent major constituents with larger amplitudes, given in brackets next to them. Hence is the same phase lag.

\begin{tabular}{|c|c|c|c|c|c|c|c|c|c|c|c|}
\hline Constit. & x000 & $\mathrm{x} 015$ & x030 & x045 & $\mathrm{x} 100$ & $\mathrm{x} 115$ & x130 & x145 & mean & $\begin{array}{l}\text { Std. } \\
\text { dev. }\end{array}$ & $\mathrm{x}$ \\
\hline MM & 85.9 & 86.4 & 85.6 & 86.2 & 85.1 & 84.6 & 83.6 & 85.4 & 85.3 & 0.84 & 85.3 \\
\hline MSF & 359.5 & 359.4 & 359.5 & 359.9 & 358.4 & 359.9 & 1.8 & 0.9 & 359.9 & 0.95 & 359.9 \\
\hline Q1 & 72.7 & 72.4 & 71.0 & 69.8 & 70.7 & 71.3 & 72.5 & 72.5 & 71.6 & 1.00 & 71.6 \\
\hline O1 & 61.0 & 60.9 & 60.9 & 60.8 & 61.0 & 60.6 & 61.0 & 60.8 & 60.9 & 0.12 & 60.9 \\
\hline M1 & 61.0 & 58.8 & 59.9 & 64.5 & 62.1 & 66.9 & 65.7 & 62.3 & 62.6 & 2.66 & 62.7 \\
\hline *PI1 (K1) & 74.8 & 74.7 & 74.7 & 75.1 & 75.3 & 75.3 & 75.1 & 75.0 & 75.0 & 0.24 & 75.0 \\
\hline$* \mathrm{P} 1 \quad(\mathrm{~K} 1)$ & 74.8 & 74.7 & 74.7 & 75.1 & 75.3 & 75.3 & 75.1 & 75.0 & 75.0 & 0.24 & 75.0 \\
\hline K1 & 74.8 & 74.7 & 74.7 & 75.1 & 75.3 & 75.3 & 75.1 & 75.0 & 75.0 & 0.24 & 75.0 \\
\hline *PSI1 (K1) & 74.8 & 74.7 & 74.7 & 75.1 & 75.3 & 75.3 & 75.1 & 75.0 & 75.0 & 0.24 & 75.0 \\
\hline *PHI1 (K1) & 74.8 & 74.7 & 74.7 & 75.1 & 75.3 & 75.3 & 75.1 & 75.0 & 75.0 & 0.24 & 75.0 \\
\hline J1 & 100.6 & 97.3 & 103.5 & 112.7 & 107.3 & 106.1 & 104.1 & 100.9 & 104.1 & 4.44 & 104.1 \\
\hline OO1 & 161.9 & 157.7 & 157.4 & 161.5 & 160.0 & 159.9 & 162.3 & 161.8 & 160.3 & 1.78 & 160.3 \\
\hline *2N2 (N2) & 329.9 & 329.0 & 329.3 & 328.9 & 328.6 & 328.3 & 329.1 & 330.2 & 329.2 & 0.60 & 329.2 \\
\hline MU2 & 44.8 & 44.7 & 45.8 & 48.1 & 46.0 & 45.1 & 44.6 & 46.4 & 45.7 & 1.11 & 45.7 \\
\hline N2 & 329.9 & 329.0 & 329.3 & 328.9 & 328.6 & 328.3 & 329.1 & 330.2 & 329.2 & 0.60 & 329.2 \\
\hline *NU2 (N2) & 329.9 & 329.0 & 329.3 & 328.9 & 328.6 & 328.3 & 329.1 & 330.2 & 329.2 & 0.60 & 329.2 \\
\hline M2 & 345.8 & 345.6 & 345.6 & 345.8 & 345.5 & 345.2 & 345.3 & 345.7 & 345.6 & 0.18 & 345.6 \\
\hline L2 & 308.7 & 311.0 & 311.8 & 309.3 & 311.8 & 311.9 & 308.2 & 308.4 & 310.2 & 1.53 & 310.2 \\
\hline *T2 (S2) & 32.5 & 32.1 & 32.1 & 32.6 & 32.8 & 32.8 & 32.7 & 32.7 & 32.5 & 0.26 & 32.5 \\
\hline $\mathrm{S} 2$ & 32.5 & 32.1 & 32.1 & 32.6 & 32.8 & 32.8 & 32.7 & 32.7 & 32.5 & 0.26 & 32.5 \\
\hline$* \mathrm{~K} 2(\mathrm{~S} 2)$ & 32.5 & 32.1 & 32.1 & 32.6 & 32.8 & 32.8 & 32.7 & 32.7 & 32.5 & 0.26 & 32.5 \\
\hline 2SM2 & 219.4 & 218.9 & 214.7 & 208.0 & 203.8 & 199.2 & 202.4 & 215.0 & 210.2 & 7.36 & 210.3 \\
\hline MO3 & 32.2 & 26.4 & 26.2 & 25.7 & 25.2 & 27.3 & 31.0 & 32.1 & 28.2 & 2.78 & 28.1 \\
\hline M3 & 0.1 & 355.5 & 345.5 & 338.2 & 335.2 & 347.3 & 0.6 & 1.7 & 350.5 & 9.79 & 350.9 \\
\hline MK3 & 330.8 & 321.7 & 320.0 & 323.3 & 325.9 & 325.7 & 332.5 & 336.7 & 327.1 & 5.37 & 326.9 \\
\hline MN4 & 206.3 & 230.0 & 276.5 & 278.0 & 307.4 & 343.2 & 39.3 & 143.2 & 228.0 & 91.99 & 284.8 \\
\hline M4 & 163.0 & 157.4 & 157.9 & 157.1 & 155.2 & 154.0 & 159.3 & 162.3 & 158.3 & 2.96 & 158.4 \\
\hline SN4 & 336.1 & 350.6 & 0.2 & 349.1 & 354.6 & 8.3 & 21.8 & 353.9 & 356.8 & 12.80 & 358.2 \\
\hline MS4 & 251.6 & 252.7 & 254.8 & 272.9 & 253.9 & 246.6 & 245.1 & 254.9 & 254.1 & 7.90 & 253.5 \\
\hline $2 \mathrm{MN} 6$ & 343.4 & 344.9 & 345.4 & 336.2 & 326.6 & 329.3 & 322.9 & 329.9 & 334.8 & 8.32 & 335.3 \\
\hline M6 & 7.0 & 14.2 & 7.1 & 5.0 & 4.1 & 359.1 & 359.6 & 2.9 & 4.9 & 4.51 & 5.1 \\
\hline MSN6 & 40.9 & 19.8 & 13.3 & 4.2 & 7.1 & 20.0 & 33.2 & 38.4 & 22.1 & 13.12 & 23.5 \\
\hline $2 \mathrm{MS} 6$ & 47.6 & 50.2 & 51.8 & 58.6 & 55.9 & 46.6 & 51.7 & 46.1 & 51.1 & 4.16 & 50.6 \\
\hline 2SM6 & 120.5 & 99.6 & 97.2 & 59.7 & 80.5 & 64.4 & 87.3 & 100.3 & 88.7 & 18.83 & 89.6 \\
\hline
\end{tabular}

to head) and tendency of the two waves to set up standing modes (Shetye 1999; Nayak and Shetye 2003).

Figure 4 shows how amplitude and phase lag of the most important tidal constituents (amplitude greater than $10 \mathrm{~cm}$ at the mouth) grow from mouth to head before topographic effect comes into play. Before the topographic influence is felt, amplitude of $\mathrm{M}_{2}$ increased by about $20 \%$ in the Mandovi from mouth to head, and by about $30 \%$ in the Zuari. The increase in $\mathrm{K}_{1}$ was by about $10 \%$ in the Mandovi and $15 \%$ in the Zuari. Phase lag increased from mouth to head for both diurnal and semidiurnal constituents. However, this variation was not linear with respect to distance from the mouth. A linear variation would have been expected if the reflected wave was absent. Further studies are needed to determine how the three processes friction, geometric effect and co-oscillation of incident and reflected wave - set up the variation seen in figure 4.

\subsection{Decay of tidal amplitude due to increase in channel elevation}

Each of the 7 panels in figure 5 gives a section of the channel topography and water level along a line drawn through the middle of the Mandovi 


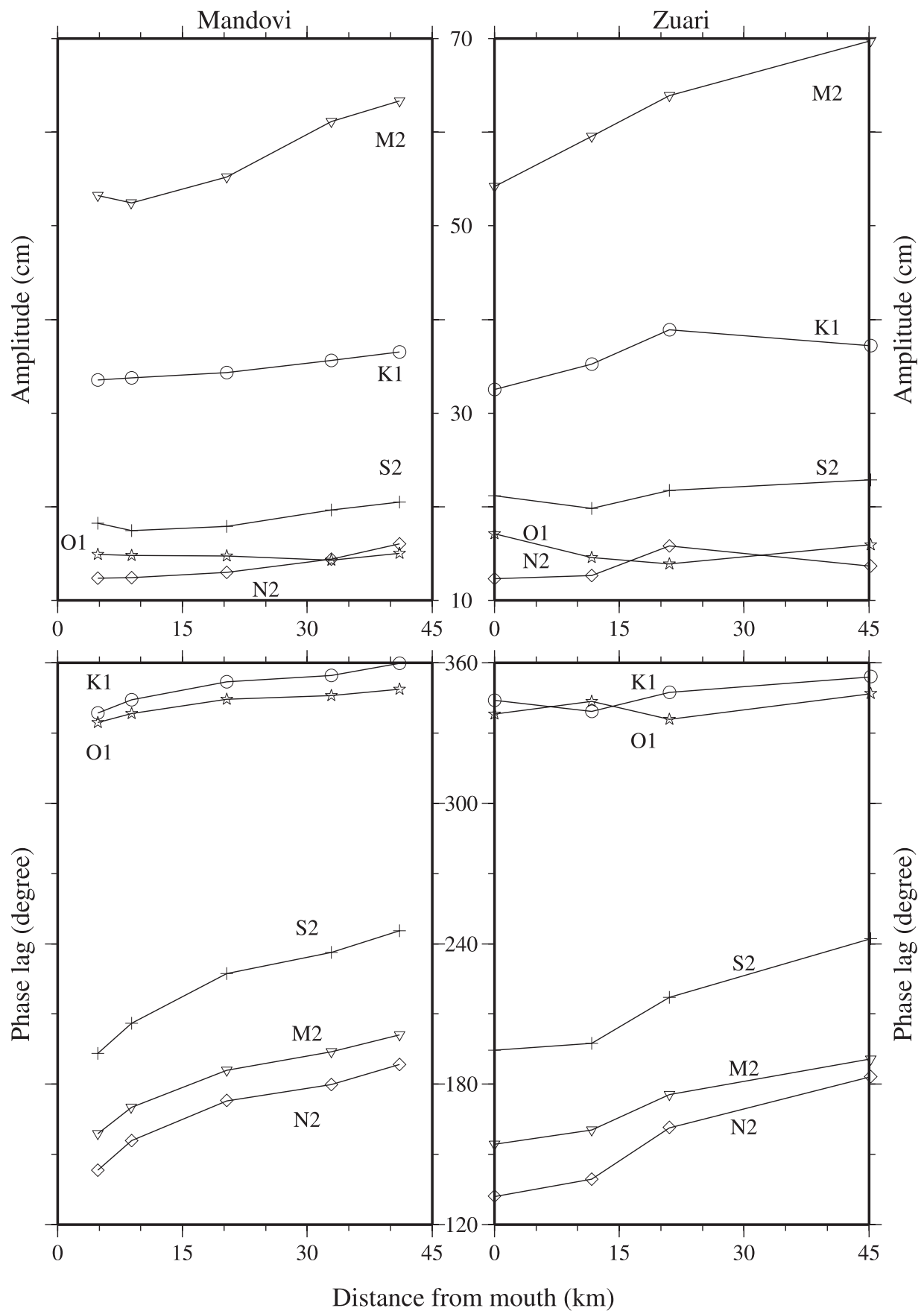

Figure 4. Variation in amplitude $(\mathrm{cm})$ and phase lag in degree (referenced to IST) of $\mathrm{M}_{2}, \mathrm{~S}_{2}, \mathrm{~N}_{2}, \mathrm{~K}_{1}$ and $\mathrm{O}_{1}$ in the main channels of the Mandovi and Zuari estuaries.

channel. Both the topography and the water level are based on observations: the topography is the same as that described in Shetye et al (1995), and the water surface depicted in the figure is based on data collected during the 2003 observations. Two consecutive panels in the figure show how the water level changed during a period of two hours during spring tide. The panels together cover a typical 12-hour cycle during springs. The figure helps to visualize how the water level along the channel changes during a tidal cycle. And hence, understand how the increase in channel elevation causes the tidal amplitude to drop at the upstream end in an estuarine channel. As seen from figure 3, the magnitude of water level variation drops sharply from Usgao to Ganjem in the Mandovi and from Sanvordem to Sanguem in the Zuari. From figure 5 it is seen that the tide reaches Ganjem in the Mandovi only when the tide is high enough to overcome the effect of increased channel elevation. The impact of the tide is felt at Ganjem in panels $\mathrm{A}, \mathrm{E}, \mathrm{F}$, and $\mathrm{G}$ of the figure. In the rest 

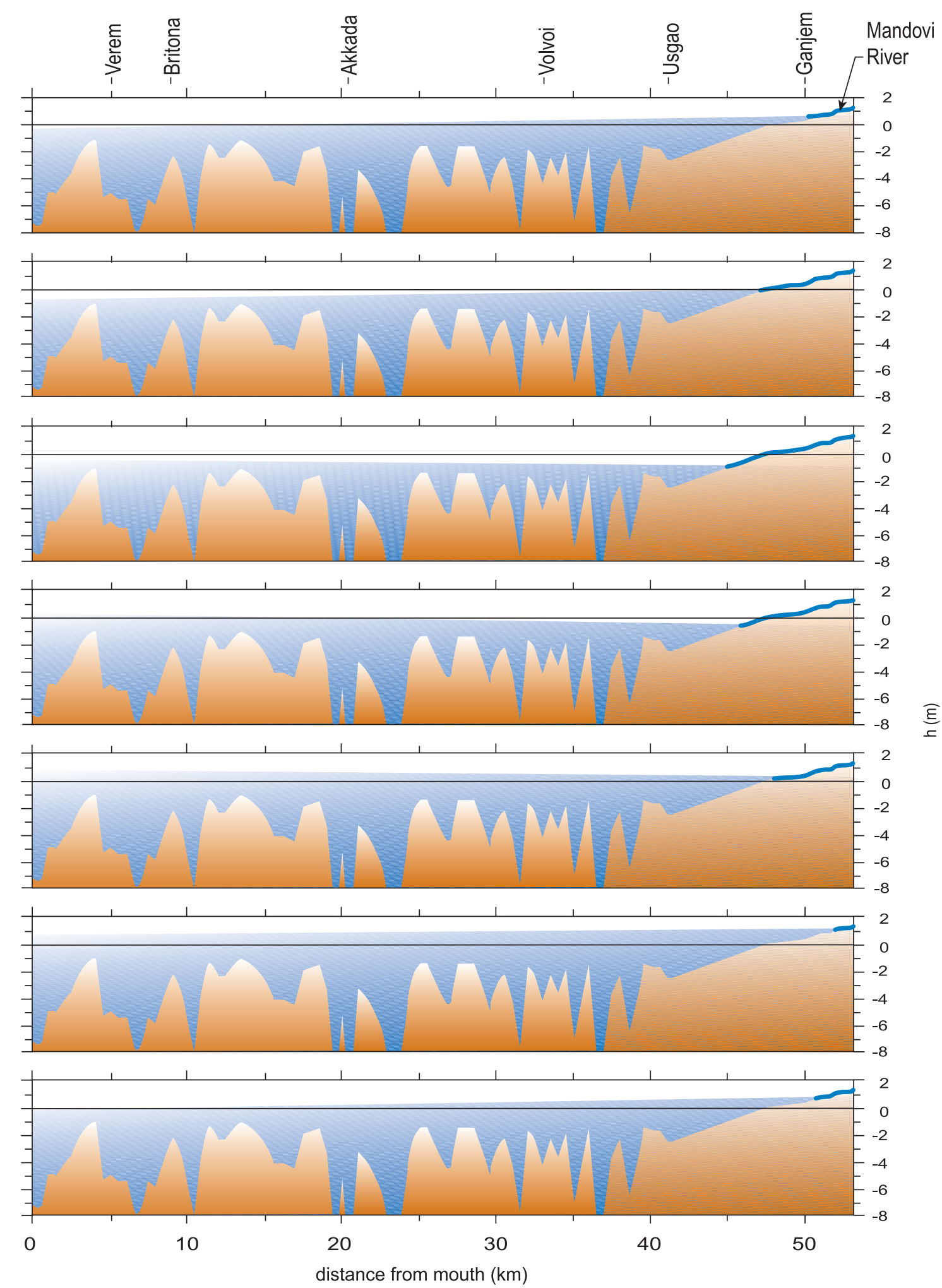

Figure 5. Each of the 7 panels in the figure gives an instantaneous section of the channel topography and water level along a line drawn through the middle of the Mandovi channel. Two consecutive panels are separated by two hours during spring tide. The water level at the upstream end is controlled by dynamics of the river flow.

of the panels no influence of the tide is seen at Ganjem and the water level is determined merely by whatever little runoff that exists in the river channel.

\section{Summary}

The Mandovi and the Zuari are typical of the estuaries found along the west coast of India. The 
estuaries are fed at the upstream end by rivers that originate on the slopes of the Western Ghats. In this paper we have described how the characteristics of tidal constituents change from mouth to head in these shallow ( $\sim 5 \mathrm{~m}$ deep), narrow (usually less than few hundred meters wide, except near the mouth) and converging channels. To our knowledge this is the first time that such a description is available for the west coast estuaries. The exercise was carried out using tide-pole readers numbering about fifty. The present socio-economic conditions in this part of the world still make it more economical to employ tide-pole readers rather than self-reading tide-gauges. The estimated errors in the computed values of tidal constituents are small enough to conclude that the spatial pattern of variation in tidal constituents is dependable. Hence the method of measurement still remains attractive to gain insights into dynamics of the tide propagation in this estuary.

The results of this study show that both the diurnal and semi-diurnal tidal constituents amplify in the estuarine channels, the amplification being larger in the case of the semi-diurnal constituents. It is expected that the observed amplitude results from an incident and a reflected wave, both of which get altered by channel geometry and friction. Further research is needed to determine the contribution of each wave to the observed amplitude and phase lag.

\section{Acknowledgements}

We are grateful to David Pugh and Philip Woodworth for reviewing the manuscript. Their comments have been very useful. We thank Shri Arun Y Mahale and Shri S Akerkar, DTP for their help in drawing figures 1 and 5 . This is NIO contribution 4018.

\section{References}

Bell C, Vassie J M and Woodworth P L 1998 POL/PSMSL Tidal Analysis Software Kit 2000 (TASK-2000), Permanent Service for Mean Sea Level, UK, p. 21.

Friedrichs C T and Aubrey D G 1994 Tidal propagation in strongly convergent channels; J. Geophys. Res. 99 C2, 3321-3336.

Nayak R K and Shetye S R 2003 Tides in the Gulf of Khambhat, west coast of India; Estuarine, Coastal and Shelf Science 57 249-254.

Shetye S R 1999 Tides in the Gulf of Kutch, India; Continental Shelf Research 19 1771-1782.

Shetye S R, Gouveia A D, Singbal S Y, Naik C G, Sundar D, Michael G S and Nampoothiri G 1995 Propagation of tides in the Mandovi-Zuari estuarine network. Proc. Indian Acad. Sci. (Earth Planet. Sci.) 104(4) 667-682.

Unnikrishnan K, Shetye S R and Gouveia A D 1997 Tidal propagation in the Mandovi-Zuari estuarine network, west coast of India: Impact of fresh water influx; Estuarine, Coastal and Shelf Science $\mathbf{4 5}$ 737-744. 